\title{
Analytical study of Reinforced Concrete Element strengthened with polypropylene fibers subjected to Elevated Temperature
}

\author{
Bhavana $\mathrm{B}^{1}$, Tejaswini $\mathrm{K}^{2}$ \\ 1(Assistant Professor, School of Civil Engineering, REVA University, Bangalore, Karnataka, India -560064) \\ 2(P.G Student, School of Civil Engineering, REVA University, Bangalore, Karnataka, India-560064)
}

\begin{abstract}
:
Risk of accidents due to fire is more often and has become a common occurrence leading to the loss of lives and property In this regard, the study investigates the effects of fire on concrete members reinforced or strengthened with polypropylene fibers. The amount of spalling and the extent of cracking of concrete can considerably be reduced by use of suitable amount of polypropylene fibers. In this paper, finite element software ANSYS is used for studying the temperature propagation in concrete exposed to elevated temperatures. An attempt will be done to study the impact of fire on reinforced concrete structural components considering a beam member of cross sectional dimensions $230 \mathrm{~mm} \times 600 \mathrm{~mm}$ providing clear cover according to the specifications of fire safety building code. Based on these parametric studies, results including the effects of high temperature on properties of fiber reinforced concrete together with the strength, stiffness, thermal stress, thermal strains under load and heat flux will be obtained by performing the analysis.
\end{abstract}

Keywords - Temperature, Polypropylene, fiber, Thermal analysis, clear cover, ANSYS.

\section{INTRODUCTION}

Fire safety must be absorbed as a main concern at the initial stage of a building project as it can have major impact on the design of a building $\&$ its structural form where risk of accidents due to fire may be predictable or unpredictable owing to this the damages are caused to structures. Compounds are multifunctional material systems that provide physical characteristics not available from any distinct material. They are cohesive structures made by physically combining two or more distinct materials. The application of polypropylene fiber as lamination or cover for reinforcement has expected much concentration for structural engineering. Internal bonding of 3 distinct materials can increase the flexural strength, thermal resistance and failure of structure takes more time under high elevated temperature and increase the failure time. Polypropylene fiber applied as cover to the reinforcement which is done experimental test of individual element is time consuming and the use of material may be quite costlier. Hence for the analysis of this multifunctioning compound material the finite element analysis is best method to analyze the individual element and the effect of RC element with fiber used.The major role of fibers in a composite mixture is to control cracks, improve the deformation characteristics and increase the tensile strength, toughness of the structural element. Most importantly polypropylene fiber is versatile with concrete, chemically inert,rust free, Alkali resistant, safe and easy to use.

\section{Introduction II}

Ansys software is a wide ranging finite element analysis tool for structural analysis including linear, nonlinear, static, dynamic, hydrodynamic, computational fluid dynamics, explicit and implicit methods and heat transfer studies. The Ansys simulation process is discretization of the single model element to fine element, considering material properties, boundary conditions support condition and ana loading comes under simulation process to get accurate result and 
to saves the time for the analysis of single elements different type of analysis.

\section{LITERATURE REVIEW}

N Muruli Krishna et al. [2] Studied the experimental result that concrete member exposed to different thermal conductivity with temperature and porosity as parameter and result of conductivity $\mathrm{v} / \mathrm{s}$ temperature for $10 \mathrm{~min}$ of time interval as a result until 120min the temperature did not reach the core of the reinforcement.

YakudimaAkibuGhali et al. [3] This study include behavior of steel reinforcement in reinforced concrete structure subjected to elevated temperature and analyzed experimentally and analytically using finite element analysis and validated with software Ansys and safir.As a result the bar fails at $430^{\circ} \mathrm{C}$ after 90 minutes addition of fiber time period for fire resistance increased by 30minutes and there was 3 minutes variation for analytical result.

L Dahmani et al.[1]In this paper they presented the spalling resistance of normal concrete and addition of polypropylene fiber in concrete mix with different sequenceas a result spalling of concrete is reduced and spalling effect of hardened concrete is studied.

Antony Nkem Ede et al. [1] they studied the behavior of RC structure after adding coconut husk fiber and polypropylene fibers while casting and exposed to $200^{\circ} \mathrm{C}$ to $1000^{\circ} \mathrm{C}$. As a result there is an increase in compressive strength, fire resistance of the structure.

T.Subramani et al. [1] analytical and experimental study carried out to find the behavior of concrete in addition of glass fiber reinforced polymer as cover to the structural element. As a result addition of glass fiber reinforced polymer gives better stiffness less deformation high strength less stess and strain value compare to only concrete.

\section{METHODOLOGY:}

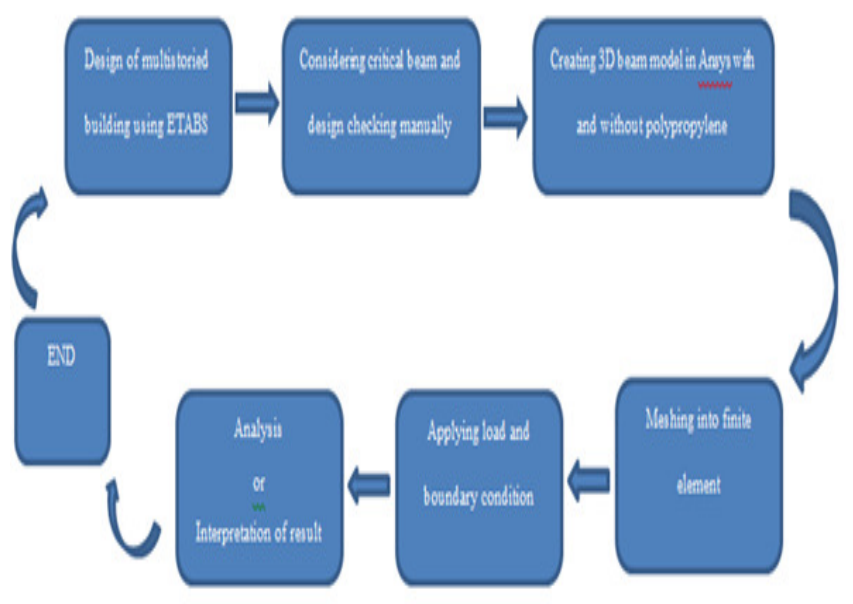

Parameters considered:

- Clear cover according to fire code and IS456

- Materials considered

- Different faces exposed to fire

\section{Modeling geometry and analysis}

In our work two models are modeled and analyzed using finite element analysis software. One model of beam with two composite material and another model of beam with three composite material. One beam with $30 \mathrm{~mm}$ clear cover according IS:456-2000, fig. 1 and without polypropylene and another beam with clear cover of $60 \mathrm{~mm}$ according to fire safety code fig.2 and with polypropylene fiber sheet of $10 \mathrm{~mm}$ thick that is covered around steel reinforcement. Material properties are mentioned below in Table.1, Table. 2 and Table.3 


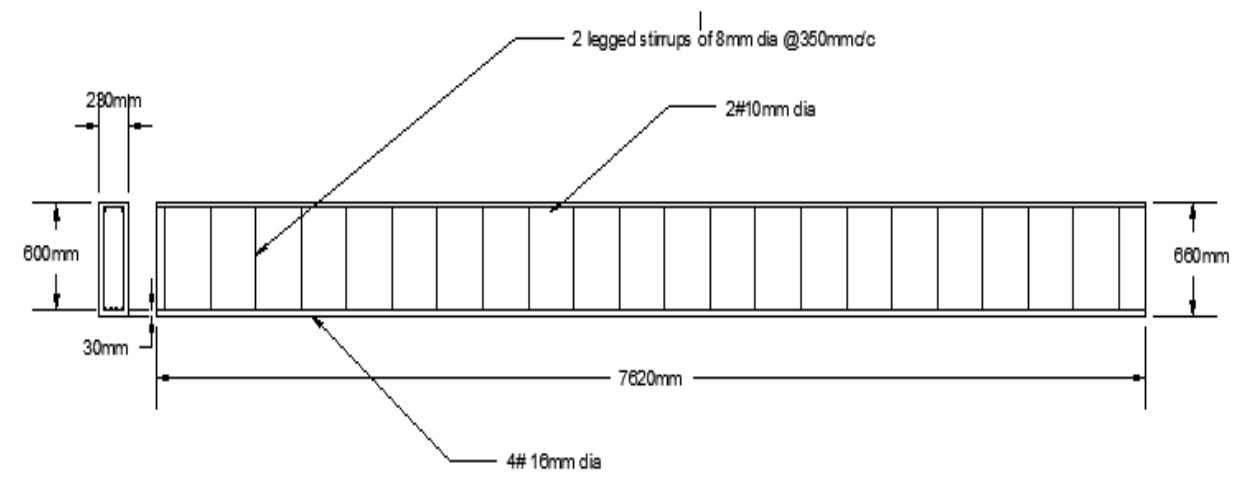

Fig.1 Beam 30mm clear cover

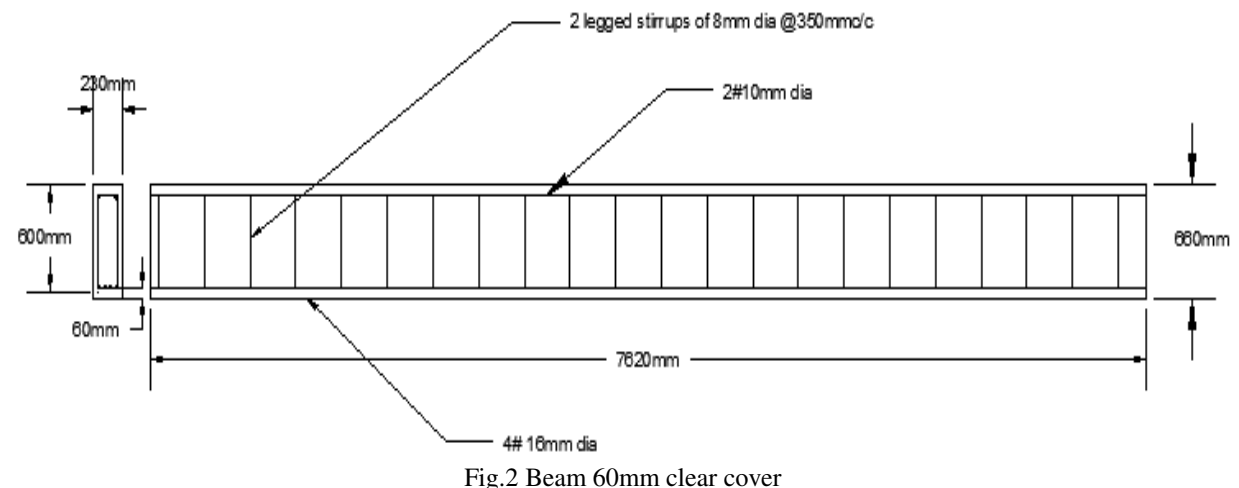

Fig. 2 Beam $60 \mathrm{~mm}$ clear cover

TABLE.1: MATERIAL PROPERTIES FOR CONCRETE

\begin{tabular}{|l|l|l|l|}
\hline Sl.No & Property & Value & Units \\
\hline 1 & Density & 2300 & $\mathrm{~K} / \mathrm{m}^{3}$ \\
\hline 2 & Young's modulus & 30000 & $\mathrm{MPa}$ \\
\hline 3 & Poisson's ratio & 0.18 & \\
\hline 4 & Thermal conductivity & 0.72 & $\mathrm{w} / \mathrm{m} /{ }^{\circ} \mathrm{C}$ \\
\hline 5 & Tensile ultimate strength & 5 & $\mathrm{MPa}$ \\
\hline 6 & Compressive ultimate strength & 41 & $\mathrm{MPa}$ \\
\hline 7 & Coefficient of thermal expansion & $1.4 \times 10^{-5}$ & $/{ }^{\circ} \mathrm{C}$ \\
\hline
\end{tabular}

TABLE.2: MATERIAL PROPERTIES FOR STEEL

\begin{tabular}{|l|l|l|l|}
\hline Sl.No & Property & Value & Units \\
\hline 1 & Density & 7850 & $\mathrm{~K} / \mathrm{m}^{3}$ \\
\hline 2 & Young's modulus & $2 \times 10^{11}$ & $\mathrm{MPa}$ \\
\hline 3 & Poisson's ratio & 0.3 & \\
\hline 4 & Thermal conductivity & 60.5 & $\mathrm{w} / \mathrm{m} /{ }^{\circ} \mathrm{C}$ \\
\hline 5 & Tensile yield strength & $2.5 \times 10^{8}$ & $\mathrm{MPa}$ \\
\hline 6 & Compressive yield strength & $2.5 \times 10^{8}$ & $\mathrm{MPa}$ \\
\hline 7 & Coefficient of thermal expansion & $1.2 \times 10^{-5}$ & $/^{\circ} \mathrm{C}$ \\
\hline
\end{tabular}

TABLE.3: MATERIAL PROPERTIES FOR POLY-PROPYLENE FIBERS 
International Journal of Engineering and Techniques - Volume 4 Issue 2, Mar-Apr 2018

\begin{tabular}{|l|l|l|l|}
\hline S1.No & Property & Value & Units \\
\hline 1 & Density & 9050 & $\mathrm{~K} / \mathrm{m}^{3}$ \\
\hline 2 & Young's modulus & $1.5 \times 10^{9}$ & $\mathrm{MPa}$ \\
\hline 3 & Poisson's ratio & 0.4 & \\
\hline 4 & Thermal conductivity & 0.22 & $\mathrm{w} / \mathrm{m} /{ }^{\circ} \mathrm{C}$ \\
\hline 5 & Tensile yield strength & $2.5 \times 10^{8}$ & $\mathrm{MPa}$ \\
\hline 6 & Compressive yield strength & $2.5 \times 10^{8}$ & $\mathrm{MPa}$ \\
\hline 7 & Coefficient of thermal expansion & $1.2 \times 10^{-5}$ & $/{ }^{\circ} \mathrm{C}$ \\
\hline
\end{tabular}

\section{Creation of 3D Modeling in Ansys:}

The model has been created according to design considerations with specific material properties, loading boundary condition and resembles the original beam model with a dimension as mentioned in fig. 3 and fig.4.

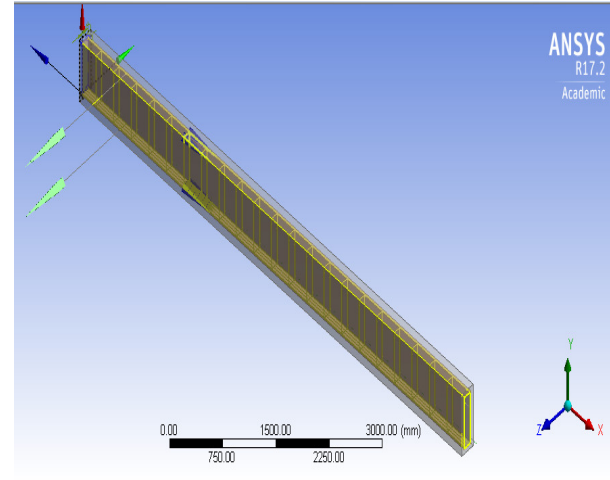

Fig. 3 Model of beam with 3 composite materials

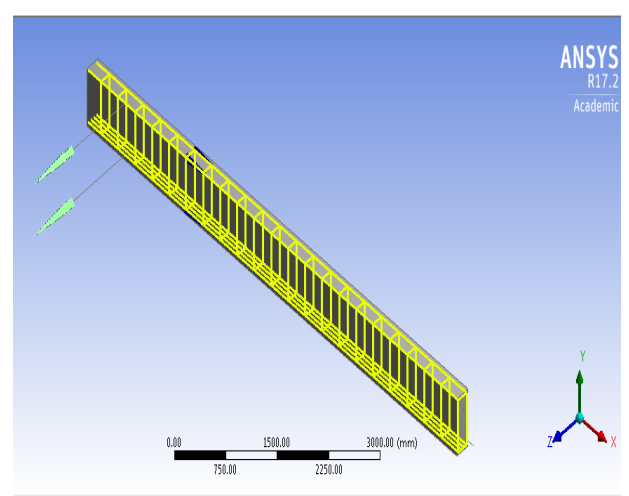

Fig.4 Model of beam with 3 composite materials

Meshing: In order to obtain the actual results from the composite RC Beam member, meshing was recommended. The beam model meshing is considered as square element of uniform size as default function.

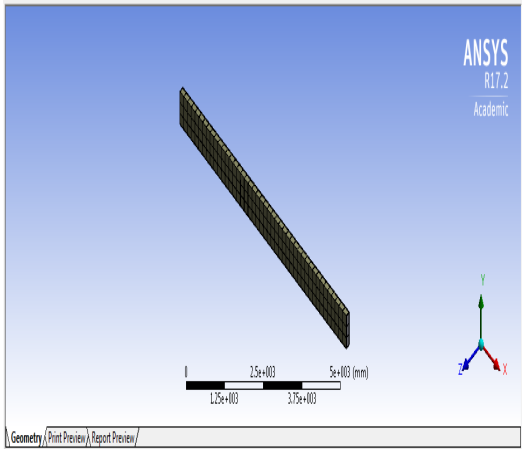

Fig.5 Meshing of polypropylene Fiber

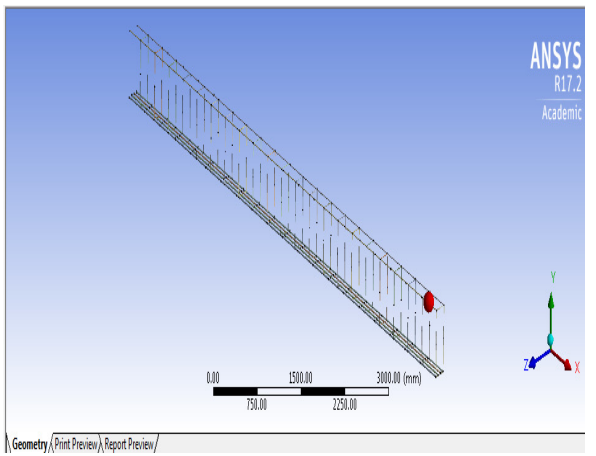

Fig.6 Meshing of Reinforcement

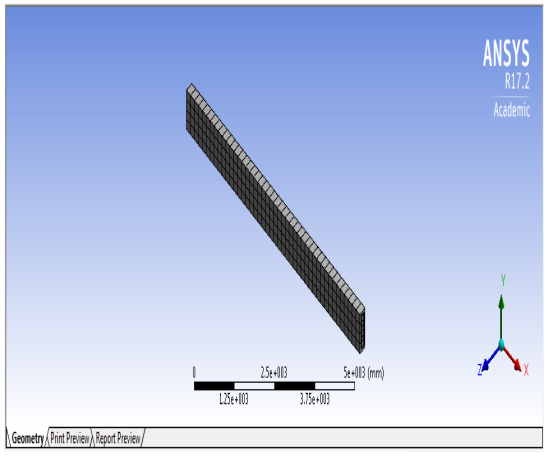

Fig.7 Meshing of concrete Element 
Boundary condition: Both the beam model is constrained to get accurate result. The support of the model is fixed at both the ends the temperature as external load applied with variation from room temperature to $1000^{\circ} \mathrm{C}$ Based on ISO 834 time temperature curve.

\section{Cases of boundary conditions applied are :}

- One face exposed to fire as shown in fig8, two faces exposed to elevated temperature as shown in fig 9, three faces expose to temperature as shown in fig 10.

- Over all body exposed to varying heat flux value as shown in fig 11.

- Over all body exposed to varying Temperature as shown in fig 12.

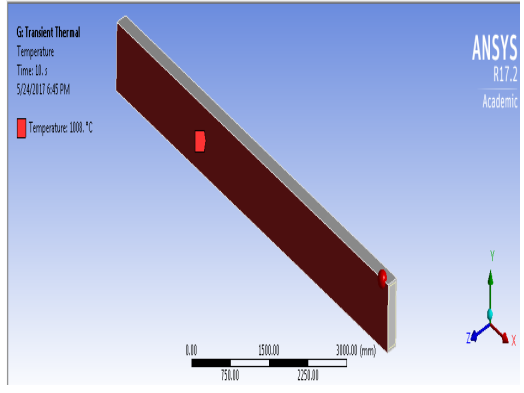

Fig.8 One face exposed to Elevated Temperature

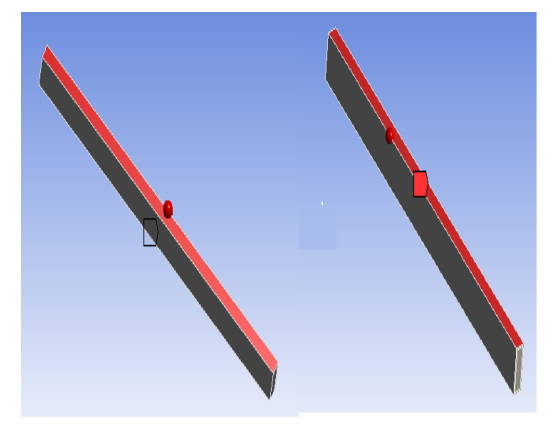

Fig.9 Two faces exposed to Elevated Temperature

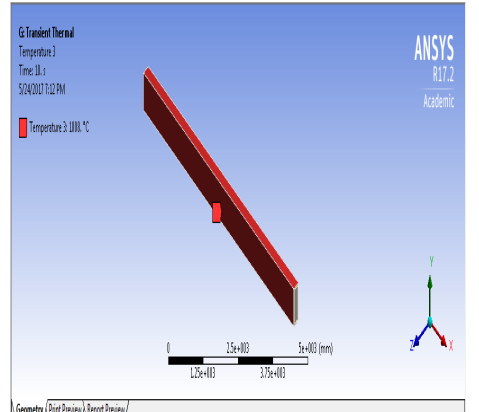

Fig.10 Three face exposed to Elevated Temperature

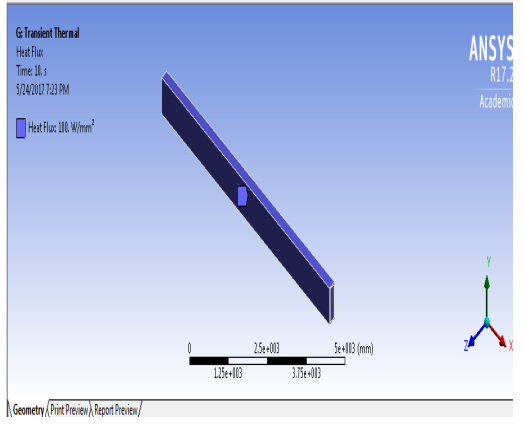

Fig.11 Over all Body Exposed to Heat flux

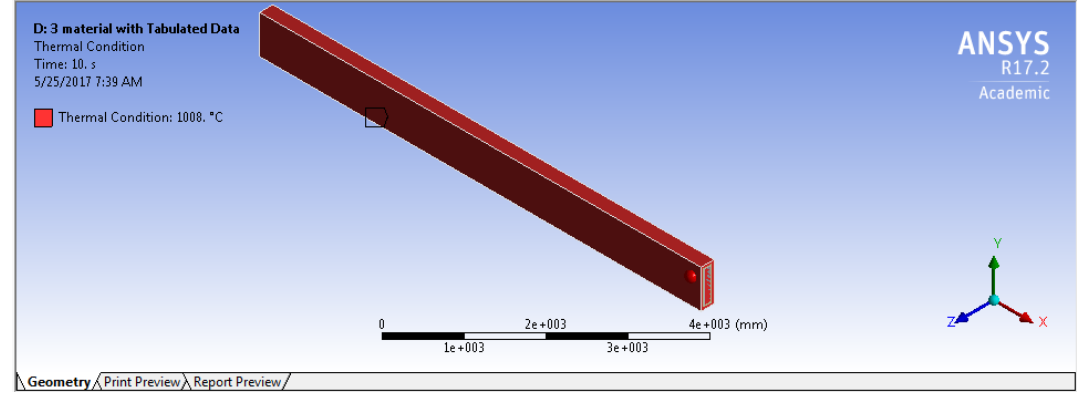

Fig.12 Over all Body Exposed to Elevated temperature
VI. Result and discussion: Based on analytical work and observation. It could be concluded that use of polypropylene fiber in the $\mathrm{RC}$ beam member increase in strength, lesser deformation and stress comparing to beam without polypropylene fiber. As a result failure occurs in the beam model without polypropylene when it reaches the temperature of $800^{\circ} \mathrm{C}$ to $1000^{\circ} \mathrm{C}$, But in case of beam with polypropylene as temperature increases and when that temperature reaches fiber melting point the polypropylene fiber melts and for a liquid layer and allows to cool the temperature in concrete and does not allow the temperature to reach Reinforcement as temperature goes on increasing failure occurs but time to reach the failure is increased. 
International Journal of Engineering and Techniques - Volume 4 Issue 2, Mar-Apr 2018

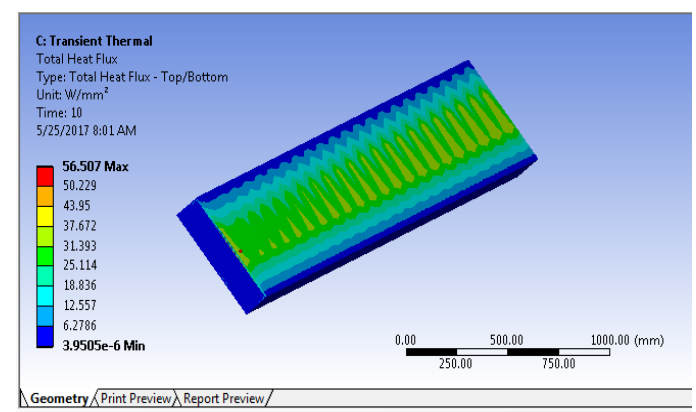

Fig.13 Beam with polypropylene reaching Heat flux of $100 \mathrm{w} / \mathrm{mm}$

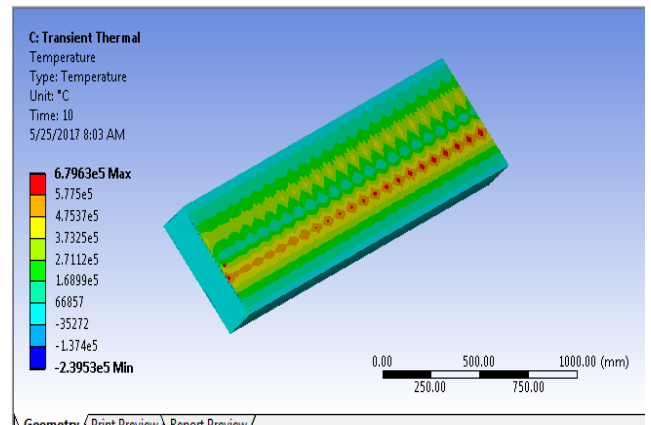

Fig. 15 Beam with polypropylene reaching $1000^{\circ} \mathrm{C}$

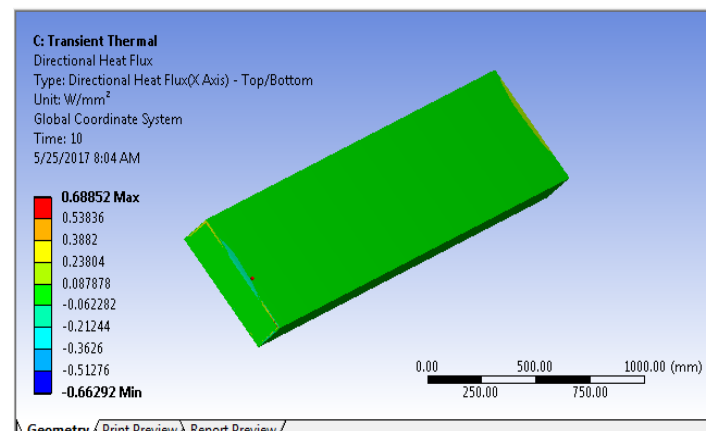

Fig.17 Beam with polypropylene showing Directional Heat flux of $100 \mathrm{w} / \mathrm{mm}$

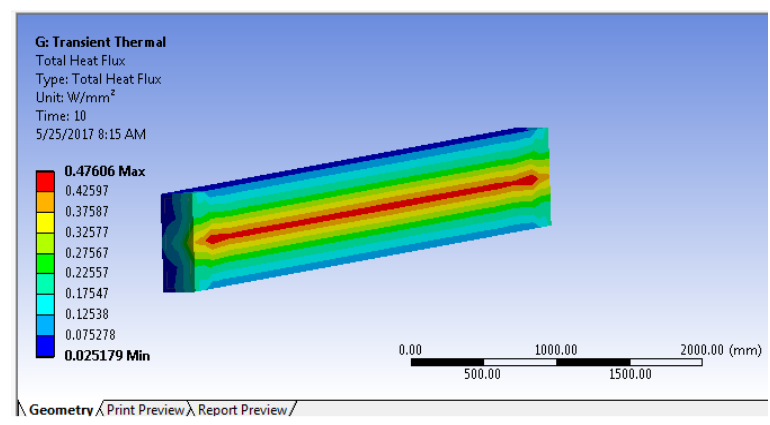

Fig.14 Beam without polypropylene reaching Heat flux100 w/mm

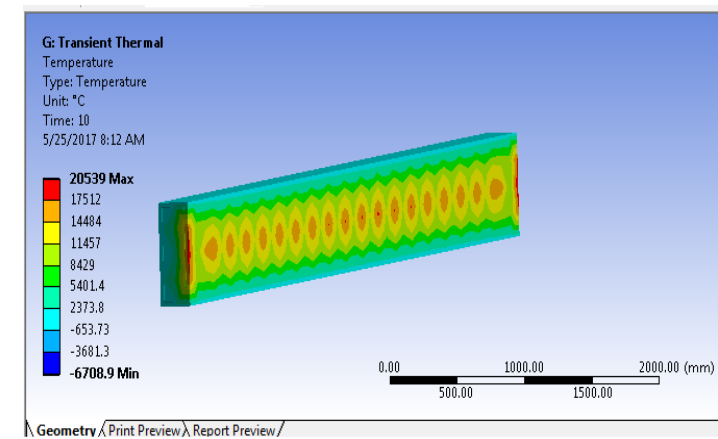

Fig.16 Beam without polypropylene reaching $1000^{\circ} \mathrm{C}$

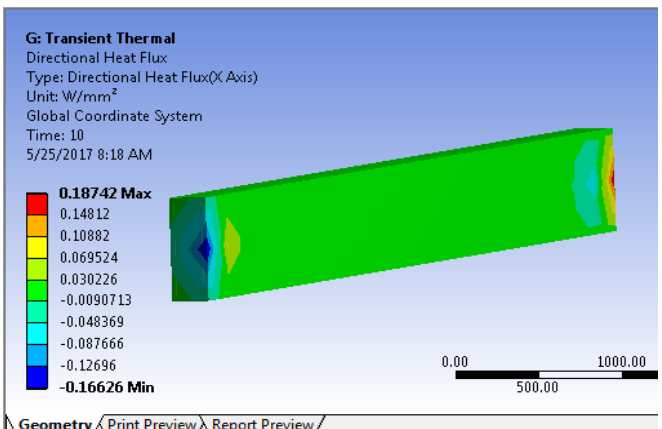

Fig. 18 Beam without polypropylene showing directional Heat flux $100 \mathrm{w} / \mathrm{mm}$

Deformation: Fig.19 and Fig.20 shows the deformation for beam member with and without polypropylene fiber as cover to RC beam member which shows more stiffer and less deformation in the model with polypropylene.

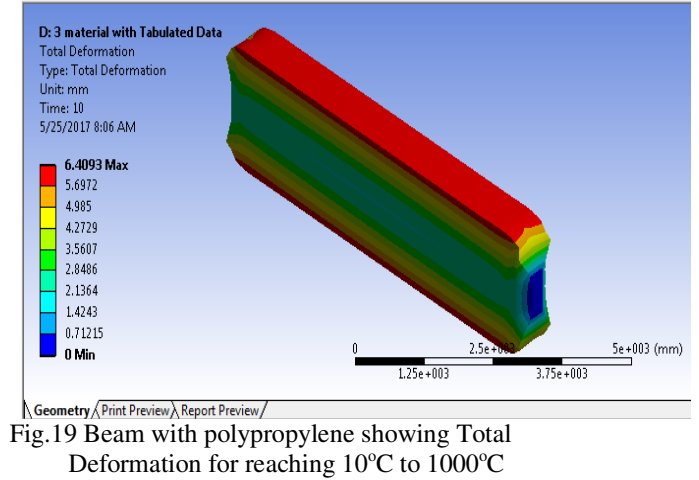

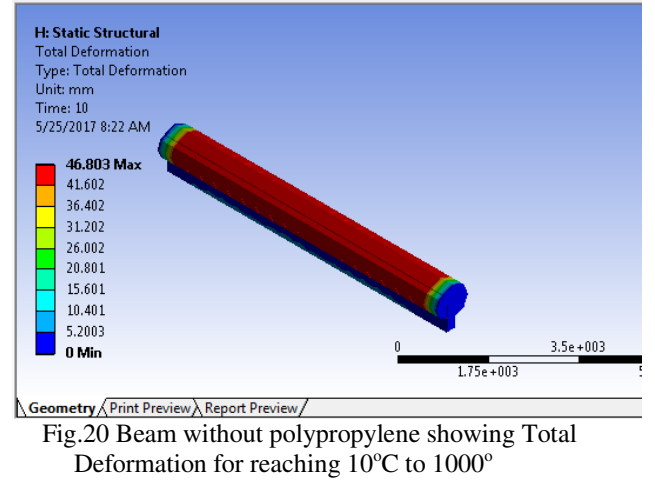



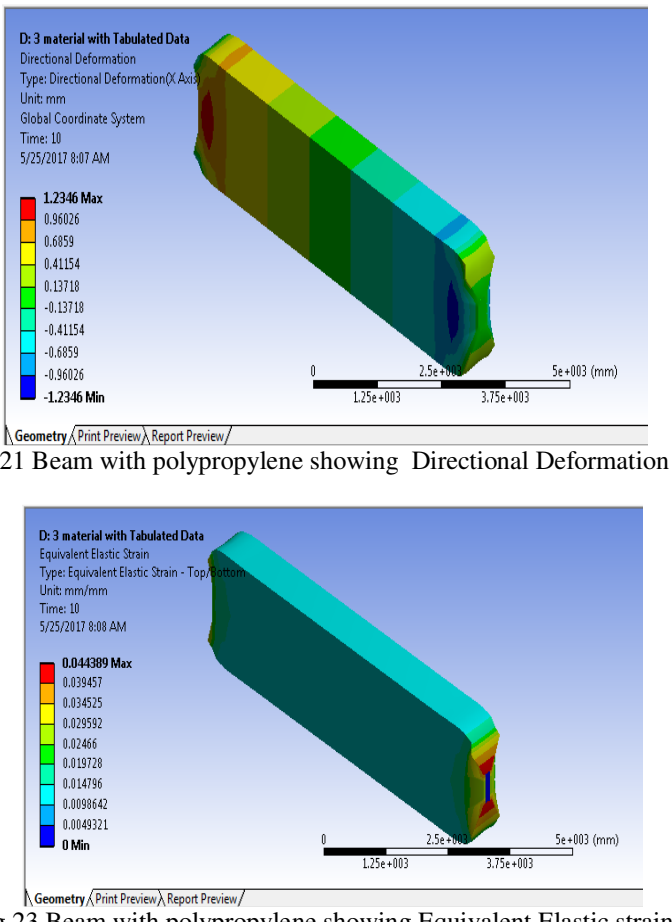

Fig.23 Beam with polypropylene showing Equivalent Elastic strain

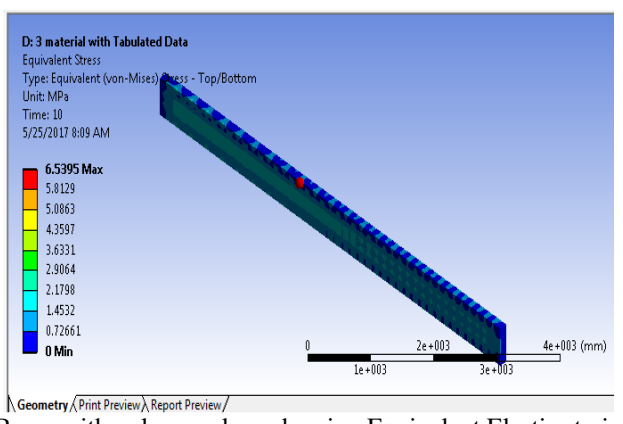

Fig.25 Beam with polypropylene showing Equivalent Elastic strain

\section{CONCLUSIONs:}

- As a result use of polypropylene as cover analytically proved there is an increases in strength, stiffness, time to reach failure.

- Ultimate strength carrying capacity of beam with polypropylene is more when compare to beam without polypropylene fiber.

\section{REFERENCES:}

1. Impact of fire on steel reinforcement in reinforced concrete structure IJSRP, volume 5, issue 10, ISSN: 2250-3153.

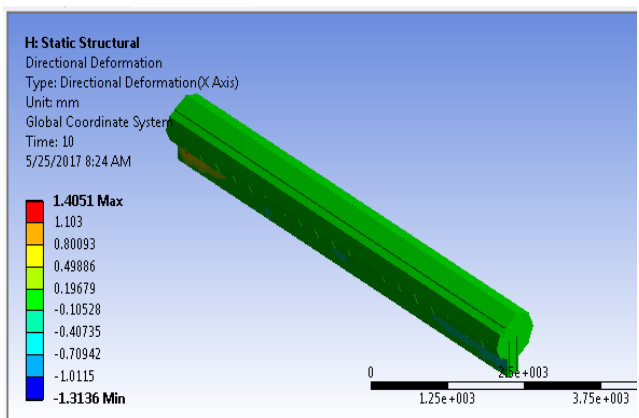

$\triangle$ Geometry $/$ Print Preview $\lambda$ Report Preview/
22 Beam without polypropylene showing Directional Deformation

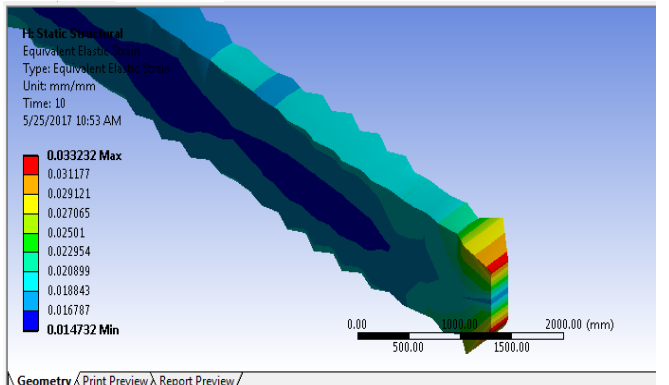

Fig.24 Beam without polypropylene showing Equivalent Elastic strain

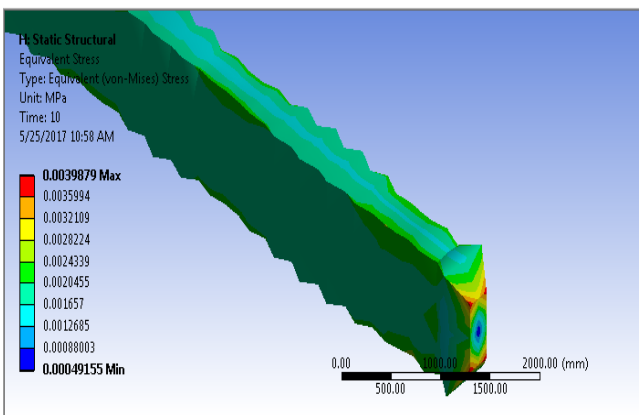

Fig.26 Beametry $/$ Print Preview $\lambda$ Report Preview/
Fithout polypropylene showing Equivalent Elastic strain

2. Study on flexural behavior of fire exposed $R C$ beams strengthened with steel wire mesh and polymer mortar IJERA, ISSN:2248-9622

3. Evaluation of fire resistance of rectangular steel columns filled with fiber reinforced concrete, volume 24, 1997.

4. Effect of temperature on strength of concrete strengthening with CFRP.H.ShehabEldil, Heba.A.Mohamed ISSN: 2319-5967 volume 2, Issue 5 September 2013. 